\title{
La Toma de Palabra del mayo 68 francés ¡Prohibido prohibir!
}

\author{
Patrick Puigmal \\ Universidad de Los Lagos, Osorno, Chile \\ Email: patrick.puigmal@ulagos.cl
}

Todos los especialistas y estudiosos de los movimientos estudiantiles y sociales que marcaron el año 1968 lo afirman: el levantamiento que se produjo en Francia durante el mes de mayo (en realidad de marzo a junio) tuvo un impacto mucho mayor que sus similares en otros países del mundo.Uno se debe interrogar sobre las razones de esta particularidad. Los cincuenta años que nos separan de este evento permiten esbozar explicaciones y también señalar efectos a largo plazo.

Francia en 1968 es un país dominado por la Quinta República gestionada y dirigida por el general Charles de Gaulle. Es un gobierno autoritario, en ciertos aspectos cercano a una dictadura, en particular en cuanto a la ausencia casi total de libertad de prensa. El gobierno controla el único canal público de televisión con un ministro de la comunicación todopoderoso llamando a los periodistas en pleno noticiero para terminar con una noticia o imponer otra. Las radios públicas son organismos de propaganda y existen solamente dos radios privadas, Europa 1 y RTL (Radio Televisión de Luxemburgo), quienes tratan, con muchas dificultades, de reportear la realidad. Por lo tanto, no es sorprendente ver que dos de los eslóganes más famosos del mayo francés son “¡Apaguemos el televisor, abramos los ojos!” y "La policía les habla todas las noches a las 20h”.

Francia es un país donde la juventud no tiene espacio de participación social. El baby-boom post segunda guerra mundial ha traído una multitud de jóvenes a las universidades. En veinte años, el país pasó de 20\% de su juventud en educación superior a casi $40 \%$. La juventud está mejor formada, mejor preparada, probablemente más analítica, pero no encuentra los espacios sociales de expresión y de existencia. ¡Hablamos entonces del mayo de 68 como de una revolución generacional! No hay tampoco espacio de participación para las mujeres. Desde el derecho de voto que obtuvieron en 1948, nada ha avanzado. No hay debate sobre las diversidades sexuales, sobre el género y, más generalmente, sobre las libertades sexuales.

Francia es una sociedad clasista donde el obrero no tiene lugar para expresar su opinión o ejercer influencia a pesar de existir un Partido Comunista (PC) con 20-25\% de votación en las elecciones y un sindicato, la CGT (Confederación General de los Trabajadores), cercano al PC, omnipresente 
en el mundo obrero. Estalinistas de ideología, los dos quieren mantener el estatus-quo (con un cuarto de los votos su influencia es enorme en el país) y harán todo lo posible para entorpecer el movimiento social, aún más cuando los estudiantes obtendrán el apoyo de muchos obreros.Esta alianza estudiantes/obreros provocará numerosas huelgas y una parálisis casi completa del país durante tres semanas en mayo.

Estamos entonces bien lejos de la república simbólica fruto de la Revolución Francesa basada en Libertad, Igualdad y Fraternidad. Concretamente, hay poca libertad, poca igualdad y casi nula fraternidad. A pesar del fuerte crecimiento postguerra, de la casi ausencia de desempleo, el país está moralmente estancado, sin espacios de participación y donde el individualismo del modelo económico imperante se ha impuesto.

Además, el país acaba de vivir dos terribles guerras/derrotas de descolonización, en Indochina y en Argelia; la moral nacional está en el piso y, por lo tanto, muchos llaman a un reforzamiento de la simbólica nacionalista. Todo lo contrario a lo que plantean los estudiantes en las calles con los eslóganes “ ¿Las fronteras nos dan igual!”o “El patriotismo es un egoísmo de masa!”.¿Por qué esta contradicción? Una parte de la juventud ha sido forzada, a través del servicio militar obligatorio, a combatir en Argelia. No obstante, en el mismo tiempo, otra parte ha compartido los ideales de los independentistas, participando en numerosas acciones a favor del Frente de Liberación Nacional (FNL) argelino.

El mayo de 68 responde entonces a una imperiosa necesidad de destape social, cultural, político y moral que se concreta a partir de la Toma de Palabra. Esta últimarevela indudablemente el carácter profundo del movimiento y constituye la señal más evidente de lo que está pasando: para la juventud en rebeldía, todo es posible, no hay limitaciones a la reivindicación y llegó el momento para el cambio radical a fuera de las ideologías tradicionales. Esta toma de palabra debe,para sobrevivir y tener impacto, encontrar los espacios indispensables de expresión. Los muros de las universidades y de las ciudades grandes se cubren entonces de cientos de eslóganes que, más que representar un programa, sintetizan simbólicamente las aspiraciones estudiantiles. Aquí van algunos de los más reconocidos: "Debajo de los adoquines, está la playa", "Prohibido prohibir. La libertad comienza por una prohibición", "No me liberen, yo basto para eso", "La imaginación toma el poder", "La acción no debe ser una reacción sino una creación”, "Las paredes tienen orejas, sus orejas tienen paredes" o “¿Ustedes son consumidores o participantes?”.

El mayo de 68 en Francia no provocará un cambio radical inmediato de las estructuras de poder, menos del sistema económico en vigor.La reacción muy bien organizada, tanto por los conservadores que por una parte importante de la izquierda comunista, sabrá muy bien utilizar el cansancio de muchos franceses luego de varias semanas de bloqueo total del país sin pan, sin bencina y, entre otras necesidades ausentes, sin trabajo, para poner fin al movimiento. Sin embargo nada será igual en términos morales, 
valóricos y comunicativos. Hay definitivamente un antes y un después del mayo de 68. A tal punto que en 2007, Nicolás Sarkozy, candidato conservador a la elección presidencial, declara "en esta elección, se trata de saber si la herencia del mayo de 68 debe ser perpetuada o si debe ser eliminada de una vez por todas", esto con la lógica de debilitar la izquierda heredera según él del mayo. Lo más cómico de la situación es que el lema principal de su campaña “Juntos, todo es posible” venía del movimiento estudiantil del 68.

El Estado deberá prontamente liberar el espacio radiofónico permitiendo el nacimiento de cientos de radios locales o asociativas; el movimiento feminista obtendrá rápidamente sus primeras victorias: una de las más importantes será el voto de la ley de aborto sin causales en 1976 propuesta y liderada por Simone Weil, ministra del gobierno conservador de Valery Giscard d'Estaing, con el apoyo de gran parte de la izquierda. Y rápidamente el país empezará a debatir sobre la aceptación de parejas homosexuales o lesbianas y el derecho de adopción por estas mismas; los jóvenes obtendrán en 1975 el derecho de votar a los 18 años en vez de los 21; la pena de muerte será abolida en 1981 al inicio del primer gobierno de François Mitterrand y la descentralización del país constituirá uno de los proyectos prioritarios de su administración. Otro evento nacional toma lugar en 1969: la renuncia del general de Gaulle a la presidencia por no haber podido recuperar la dirección, el "control”, del país luego del mayo y haber sido derrotado en el referéndum del mismo año sobre regionalización, que había propuesto para recuperar popularidad.Esta aceleración de la liberalización moral y política de la sociedad no se explica, a juicio nuestro, sin las huellas del mayo de 68.

Además, muchos de los líderes políticos y sociales de los años 80 y 90 participaron del levantamiento de 68. Entre ellos, Alain Geismar hoy en día profesor universitario jubilado, Jacques Sauvageot director de la Escuela de Bellas Artes, Serge July creador en 1973 del diario “Liberation”, uno de los más importantes del fin del siglo XX, justamente para romper con la censura oficial de los medios de comunicación, Jean Paul Sartre escritor, Marc Kravets periodista, Tiennot Grumbach abogado, André Glucksmann y Alain Finkelkraut filósofos, Jean Luc Godard y Romain Goupil cineastas, Alain Krivine líder de extrema izquierda y Bernard Kouchner fundador de la ONG Médecins du Monde. Todos escogieron carreras profesionales relacionadas directamente a la comunicación o a la acción política en pos de la construcción de una sociedad nueva, siendo así no solamente herederos sino actores de las transformaciones propuestas por el mayo de 68 .

No obstante, el más carismático de ellos, Daniel Cohn-Bendit, vivió y sufrió en carne propia su rol predominante durante los tres meses del levantamiento. Su origen judío de nacionalidad franco-alemana (sus padres antinazis se refugiaron en Francia en 1933), su adopción de la nacionalidad alemana para escapar al servicio militar obligatorio francés y su anarquismo, lo transforman rápidamente en el enemigo público n ${ }^{\circ} 1$. Dany el rojo,como rápidamente lo identifican y nombran, lidera, con otros,el movimiento desde su inicio el 22 de marzo en Nanterrehasta el final en junio y es expulsado 
con prohibición de volver a Francia(prohibición ilegal, siendo francés), que será levantada solamente en 1978. Nace en ese entonces uno de los últimos eslóganes del mayo: “iTodos somos judíos alemanes!”. Cohn-Bendit se orienta entonces hacia la autogestión política en Alemania en un primer tiempo y, luego, hacia la ecología reformista llegando a representar los partidos verdes en el parlamento europeo desde el año 1994. Partidario de una Europa sin fronteras nacionales pero con regiones afirmadas y con una constitución política federal, Cohn-Bendit se define hoy como un libertario liberal, pero siempre guarda un pie en 68, declarando por ejemplo, "En 68, Francia era un país optimista; hoy es un país muy pesimista. ¡Mayo del 68 no podría haber ocurrido en la Francia pesimista actual! ${ }^{1}$

Se han hecho recientemente comparaciones entre el mayo 68 de Francia y el despertar ciudadano en Chile desde el año 2006 a través, en particular, las numerosas manifestaciones estudiantiles. Creemos que la comparación es válida solamente en lo relativo a la toma de palabra. Los contextos son tan distintos que comparar estos eventos parece relevar más de un intento de recuperación simbólica que de un estudio serio. Aun así, esta toma de palabra de la sociedad chilena es un fenómeno que está cambiando la vida del país, que está marcando profundamente los programas y el actuar de los partidos y líderes políticos y que, también, hace viajar los chilenos desde el consumismo brutal a un rol más ciudadano y activo. Algo, entonces, parecido a lo que ocurrió en Francia luego del mayo de 1968.

\section{Agradecimientos}

Este texto se elaboró a partir de la exposición presentada por el autor en el seminario «El cielo por asalto : mayo del 68 en perspectiva histórica» organizado por el Departamento de Historia de la Universidad de Santiago de Chile (USACH) el 24 de mayo de 2018 en Santiago. 


\section{Nota}

${ }^{1}$ Velasco Irene, Entrevista a Daniel Cohn-Bendit «Tenemos que reinventar la democracia con fantasia», El Mundo, Madrid, 7 de mayo de 2017. 